\title{
Histórias dos USOS, DESUSOS E USURA DOS CORPOS NO CAPITALISMO
}

\author{
Rômulo Frota da Justa Coelho ${ }^{\star}$ \\ Maria de Fátima Vieira Severiano ${ }^{\star \star}$
}

\begin{abstract}
RESUMO
Este artigo empreende uma reflexão teórico-crítica sobre os usos do corpo humano ao longo das diferentes etapas do capitalismo, desde seu surgimento, na Era Moderna, até a contemporaneidade, considerando-se as lógicas da produção e do consumo. Ao fim deste processo, argumentamos que o atual corpo hedônico, supostamente liberto de amarras morais e disciplinares, ainda carrega, como inconvenientes hematomas, todas as marcas deixadas pelos diferentes usos e desusos que sofreu ao longo do capitalismo. Por fim, questionamos brevemente as possibilidades de novas batalhas serem travadas a fim de que reinventemos corpos possiveis e desejáveis, para além das lógicas de submissão e controle.
\end{abstract}

Palavras-chave: Corpo. Capitalismo. Modernidade. Pós-modernidade. Subjetividade

\section{Histories OF THE USES, DISUSES AND USURY OF THE BODIES IN THE CAPITALISM}

\begin{abstract}
This article undertakes a critical-theorical reflection on the uses of the human body throughout the different stages of the capitalism, since it's sprouting, in the Modern Age, until the contemporary's days, considering the logic of production and consumption. At the end of this process, we argue that the current hedonic body, supposedly free of the chains of moral and discipline, still carries, as
\end{abstract}

* Aluno do Curso de Graduação do Departamento de Psicologia da Universidade Federal do Ceará. Bolsista PIBIC-CNPq.

* Psicóloga, Doutora em Ciências Sociais Aplicadas à Educação pela UNICAMP e Universidad Complutense de Madrid. Professora (Adjunto) do Departamento de Psicologia da Universidade Federal do Ceará. Coordenadora do Mestrado em Psicologia - UFC

Endereço: Av. Rui Barbosa, nº 640, Apto. 601. Bairro: Meireles. CEP: 60.115-220. Fortaleza-CE.

E-mail: fatimasev@terra.com.br

Fonte de financiamento: bolsa PIBIC-CNPq, pertencente ao aluno referido. 
inconvenient stains, all the marks left for the different uses and disuses that it suffered throughout the diverse phases of the capitalism. Finally, we briefly question the possibilities of fighting new battles se that we can recreate possible and desirable bodies, far beyond the logics of submission and control.

Keywords: Body. Capitalism. Modernity. Post modernity. Subjectivity.

\section{INTRODUÇÃO}

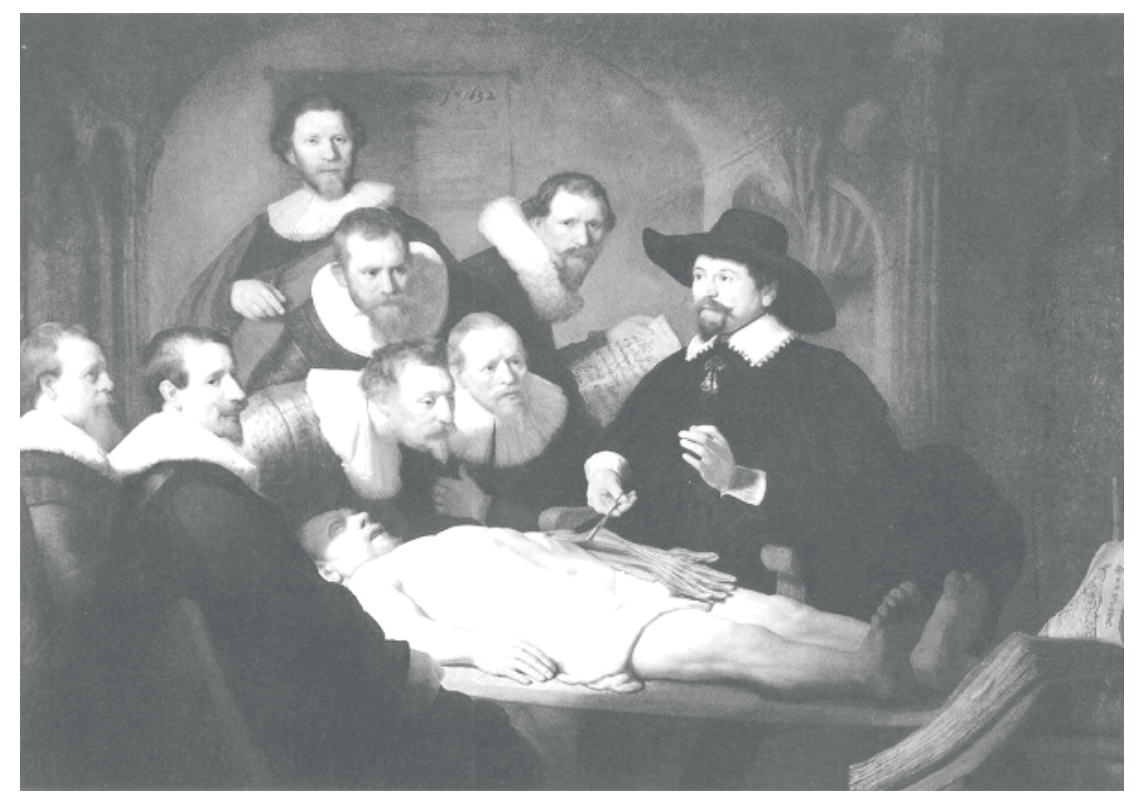

The anatomy lesson of Dr. Nicolaes Tulp - Rembrandt (1632)

O bisturi cinde a carne, abre-a com maestria. O gesto do Doutor Tulp é emblemático. Ali, naquele anfiteatro, diante de distintos e esclarecidos senhores da fina burguesia holandesa, ele é o sábio guia a perturbar o silêncio e a penumbra daquelas vísceras, a purgar os segredos daquele corpo. Do corte cirúrgico não se evaporou nenhuma essência etérea, nenhuma alma ou sopro divino, nenhum miasma, nenhum selo do Criador. A um século deste quadro de Rembrandt (1632), tais pensamentos talvez não seriam de todo descabidos. Mas Doutor Tulp e sua curiosa platéia respiram outros ares. Estamos no século XVII, ou, como preferem alguns, em plena Modernidade.

A Idade Moderna inaugura uma série de rupturas e revoluções nos mais diversos campos da atividade humana (FIGUEIREDO, 2000; BAUMAN, 2001; HARDT; NEGRI, 2004). Entre os século XV e XVII, na Europa Ocidental, o regime feudal e teocrático vigente durante toda a Idade Média vai sendo minado 
por uma série de transformações sócio-econômicas, políticas e filosóficas. O capitalismo mercantil dilata-se para além dos burgos. Lentamente seus representantes, os burgueses, despem o rei e tomam para si a coroa e o trono da aristocracia. Novos pensamentos, novas ambições, novas filosofias já descoladas da Escolástica e sua contemplativa senhora feudal, a Igreja Católica. O corpo, vetor material de todas estas transformações, acede a novas concepções e percepções.

O presente estudo pretende empreender uma análise crítica acerca dos diversos regimes de corporeidade vigentes no modo de produção capitalista, desconstruindo a idéia de um "corpo-natural", hipostasiado de suas condições culturais e sócio-históricas. Concordamos com Le Breton (2003) em sua afirmativa de que o corpo não existe em estado natural, mas se encontra sempre imerso em uma trama de sentidos, objeto de múltiplas representações e imaginários, a partir dos quais se evidencia uma dada relação do sujeito com o mundo. Reconhecendo, portanto, que a análise do corpo constitui-se sempre em uma tarefa extremamente complexa, na medida em que envolve uma gama extensa de disciplinas que fazem fronteira entre as ciências biológicas, humanas e sociais, tomaremos como fio condutor de nossas análises as formas de controle do corpo pelos dispositivos capitalistas das sociedades ocidentais e suas instituições reguladoras, privilegiando as dimensões da produção e do consumo. Ou seja, os diversos registros do corpo serão refletidos sob o prisma da lógica capitalista, seja no papel de corpoprodutor, seja no de corpo-consumidor, buscando desvelar nas múltiplas visões e concepções de cada época, as formas de coação e as estratégias de produção de subjetividades então empreendidas.

A análise das formas de ordenamento, de educação, de disciplina, de modelagem e de publicização do corpo através da história é de natureza eminentemente crítica, pois intenta apontar relações de poder veladas nos bastidores dos fenômenos em estudo, no intuito de desnaturalizá-los e relançá-los no seu devido devir histórico.

\section{O CORPO NA MODERNIDADE ${ }^{1}$ - CORPO DO INDIVÍDUO E CORPO-MÁQUINA}

Definida com relação à Antiguidade, a Modernidade surge com o Renascimento europeu, em meados do século XV, implicando uma paulatina desagregação da ordem feudal e uma consolidação da ordem capitalista, o que significou uma progressiva diferenciação das esferas econômicas e administrativas do mundo social, que culminaria no moderno Estado capitalista-industrial. A pensar com autores como Marx (1984) e Weber (1997), o processo de modernização social caracteriza-se, fundamentalmente, pela consolidação da economia capitalista e do Estado moderno, o que significa dizer que o modo de produção capitalista constituiu-se no grande marco diferenciador da era moderna. Apesar do termo "modernidade" ter sido cunhado no século XIX, ${ }^{2}$ a idéia de ruptura a ele relacionada, já estava presente desde o início da assunção da moderna sociedade burguesa, em meados do século XVI. Na esfera do pensamento filosófico, a referida ruptura significou o declínio do paradigma "cosmocêntrico-teocêntrico", no qual o homem era visto como apenas mais um ente subsumido à ordem natural do 
Cosmos, ou mais um dado no imenso arquivo pessoal de Deus, em favor de uma visão "antropocêntrica", na qual o sentido de todas as coisas passa a ser constituído pela consciência intencional do sujeito.

Nessa perspectiva "cosmocêntrico-teocêntrica", nos conta a tradição judaico-cristã que o corpo do homem viria do barro, moldado e animado pela própria Mão Divina, realização semelhante àquela de Prometeu na mitologia grega, segundo os relatos do poeta Hesíodo. Sua natureza seria holística, parte divina, parte mundana, integrada, como foi dito, a uma ordem natural maior que lhe conferiria sentido.

O bisturi do Doutor Tulp, contudo, não incide sobre este húmus divino feito corpo, não cava e revira a intimidade sagrada de uma natureza transcendente da qual o próprio também faria parte. Analisa-se a funcionalidade dos órgãos, a geometria dos ossos e a morfologia dos músculos. Não é um homem que é dissecado no leito, mas sim um aglomerado de funções e de estruturas interdependentes, uma máquina metabólica mantedora da vida sem nenhuma causa metafísica. O cadáver depositado no leito não merecera um único canto litúrgico, um réquiem por seu espírito ou uma pira funerária para sua carne.

Essa "dessacralização" do corpo é um lento e complexo processo que perpassa os principais anatomistas modernos (Vesálio, Harvey, Da Vinci) e vai ganhar seus louros epistemológicos e filosóficos na obra de Descartes, no século XVII, e em sua distinção entre substância pensante (res cogitans) e substância extensa (res extensa). À substância pensante (a mente, o espírito) caberia o papel de condição e fundamento de todo conhecimento verdadeiro possível, pois somente à consciência do sujeito cognoscente, a Verdade, mediada pela Razão, se revelaria clara e distintamente. O corpo, substância extensa, é na filosofia mecanicista de Descartes pura matéria, máquina, pouco diferindo do corpo do animal, ${ }^{3}$ tornando-se mero apêndice da mente, que busca a Verdade e constrói a Ciência. Tem-se então um corpo-objeto, um autômato, uma máquina que se oferece à sede de saber de uma consciência autônoma, transcendente, que seria a verdadeira morada do Sujeito.

O corpo aí já não participa de uma comunidade maior de sentidos, como nas estruturas societais de tipo tradicional e comunitária, não é matriz indispensável à construção das identidades grupais, mas sim um mero mecanismo passível de ser explicado segundo o modelo geral da Física da época. Essa parcela mecânica do homem deveria bastar-se, obrigada a trabalhar em silêncio para não perturbar o ofício espiritual do pensamento e da Razão, constantemente ameaçados pelas ambigüidades sensíveis da corporeidade.

Contudo, não pensemos que a partir deste momento o corpo passa a ser apagado da sociedade ocidental em prol de uma, digamos, "República de Espíritos Racionais". As proposições das filosofias mecanicistas sobre o corpo se difundem simultaneamente à emergência do capitalismo como modo de produção que substitui gradativamente o feudalismo, impondo um novo regime de corporeidade. Ao triunfo do corpo-máquina emenda-se a emergência do individualismo moderno, do corpo-indivíduo. 
Entre os séculos XVI e XVIII nasce o homem da modernidade: um homem separado de si mesmo (neste caso sob os auspícios da divisão ontológica entre o corpo e o homem), dos outros (o cogito não é o cogitamus), e do cosmos (de agora em diante o corpo não se sustenta mais que por si mesmo, desarraigado do resto do universo, encontra o fim nele mesmo, deixa de ser o eco de um cosmos humanizado). (LE BRETON apud GONÇALVES, 2002, p. 35)

Importa à burguesia e ao capitalismo nascente a existência de indivíduos "livres", melhor dizendo, trabalhadores que já não partilhem de vínculos sociais com os meios de produção comunais, provendo-lhes subsistência enquanto estivessem vinculados à sua comunidade (FIGUEIREDO, 2002). O trabalhador do capitalismo, destituído dos laços de compromissos mútuos de produção, cooperação e lealdade comunitárias do regime feudal, torna-se "forçosamente livre" para vender seu corpo (afinal, um mero aparelho a serviço da vontade de seu espírito...) como mercadoria e força de trabalho aos donos dos meios de produção, que em troca the pagam em dinheiro o suficiente para que mantenha suas engrenagens corpóreas funcionando. "Corpo do indivíduo", átomo social que é premido a buscar por si só as condições de sua sobrevivência; e "corpo-máquina", objeto de posse de um indivíduo que pode aliená-lo de si mesmo, de sua "alma", administrálo como propriedade privada e vendê-lo no mercado de trabalho. Descartes revisitado: res extensa, corpo-máquina do operário, trabalho braçal; res cogitans, indivíduo burguês, corpo pleno e cultivado, trabalho intelectual.

Com o advento da Revolução Industrial (1750) e a emergência de modernas tecnologias de produção, o corpo do trabalhador é cada vez mais solicitado como peça constituinte da engrenagem industrial capitalista. À massa de operários que se aglomera nas fábricas cabe a preciosa tarefa de operar a cara maquinaria produtora de mercadorias, bem como de adaptar-se à urbanização crescente (um cidadão não é um camponês...) e às novas condições de vida aí engendradas. Ante todas estas exigências, os corpos precisam ter suas potências dissipativas e subversivas constantemente vigiadas, administradas, para que não ponham em cheque a extensa rede de poder que os captura. Ao movimento caótico da turba de corpos vem acoplar-se todo um sistema de vigilância contínua e minuciosa, um olhar panóptico (FOUCAULT, 1999) que vigia, recompensa, pune e disciplina.

Foucault (1999) aponta o momento histórico da consolidação das sociedades disciplinares (séculos XVIII a XIX na Europa) no desenvolvimento de uma nova "anátomo-política" do corpo, na qual já não interessa somente aumentar suas habilidades e aptidões ou aprofundar sua sujeição, mas compor com os corpos relações em que a utilidade destes cresça tanto mais quanto sua docilidade e obediência sejam acentuadas. "A disciplina aumenta as forças do corpo (em termos econômicos de utilidade) e diminui essas mesmas forças (em termos políticos de obediência)" (FOUCAULT, 1999, p. 119). Toda uma tecnologia social de controle emerge a partir deste contexto disciplinar, vazando para além dos galpões das fábricas ou das casernas militares e inundando todo o espaço social. O que vemos (ou o que nos vê...) agora são arquiteturas projetadas para capturar o corpo 
numa rede ininterrupta de visibilidades. Cada gesto, postura, movimento, deve entrar numa economia rígida dos detalhes, deve ser codificado, esquadrinhado e utilizado de maneira lógica e funcional.

O objetivo é aproximar o funcionamento corporal de uma norma, de um padrão ótimo de produtividade, mas também mantê-lo num limiar aceitável de "moralidade", de complacência política, higiene e decoro sociais. Para tanto, todo um campo científico acerca-se desse corpo estratégico, analisando-o e classificando-o, pondo no lugar suas partes sobressalentes que porventura firam as normas de sua correta organização. Pedagogias do corpóreo e ortopedias do físico pululam entre os séculos XVII e XIX, conectando ao corpo-máquina uma série de roldanas, correias e polias que o exercita e modela sua silhueta. O corpo requer especialistas, técnicos autorizados e legitimados a falar em seu nome. É a era dos moldes, coletes, espartilhos e corpetes, uma série de panóplias corretoras que não se contenta com fins terapêuticos (corrigir os "infortúnios" da natureza), mas impõe e produz normas e fôrmas (SANT'ANNA, 1995). Aos desviantes, aos "anormais", acode uma série extensa de rótulos, estigmas e diagnósticos - um bestiário científico de corpos e personalidades disformes. A norma disciplinar produz identidades, individualiza corpos e modela subjetividades.

Estamos aqui há alguns passos de distância do dualismo corpo $x$ alma cartesiano. O corpo "fala" nesse regime de visibilidade, comunica aos seus observadores as condições afetivas e psíquicas do indivíduo, denuncia seus defeitos e crimes. A alma cola-se à anatomia, insinua-se à flor da pele. Não é à toa que os séculos. XVIII e XIX assistem à expansão da antropometria, ciência calcada em métodos de análise do corpo humano visando à definição de analogias entre a anatomia e os caracteres dos comportamentos dos indivíduos e das raças (PERROT, 1991). J. C. Lavater (1741-1801), na Suíça, refunda a Fisiognomia, ciência que se incumbe de estabelecer correlações entre formas corporais e características espirituais (FIGUEIREDO, 2002). Broca (1824-1880), na França, e Gall (1758-1828), na Alemanha, elaboram instrumentos para a medição de crânios no intuito de elaborar medidas exatas entre as dimensões ósseas e a aptidão ou inaptidão de grupos humanos para a vida em civilização. Cesare Lombroso (1835-1909), na Itália, constrói toda uma topologia, na qual saliências e protuberâncias anormais no crânio e na mandíbula podem denunciar personalidades agressivas e ideações criminosas ("o criminoso-nato"). Na trama cotidiana, o pudor vitoriano oculta o corpo sob pesadas anáguas, espartilhos e fraques, tanto como forma de distinção social quanto como esquiva à exibição do que é mais íntimo e individual: o corpo e seus signos.

O século XVIII vê germinar uma nova tecnologia do poder que já não incide apenas sobre o corpo do indivíduo, mas sobre o homem-espécie, sobre o conjunto de processos biológicos que engendra e sustenta a vida das populações humanas. Os mecanismos de regulamentação destes processos vitais (taxas de natalidade, morbidade, levantamentos demográficos, salubridade dos ambientes etc.) exigem uma nova tecnologia de poder, íntimo tanto dos corpos em suas individualidades quanto em suas generalidades de espécie e população. Foucault denomina "biopoder" esta nova forma de controle que se incumbe de gerir a vida, de assegurá- 
la e segurá-la dentro de padrões médios de homeostase social. Administrar os fenômenos populacionais, ajustando-os aos processos econômicos, torna-se essencial ao desenvolvimento do capitalismo (FOUCAULT, 2005). A medicina ocupa um cargo privilegiado nesse projeto biopolítico, pois tanto ausculta o corpo loquaz dos indivíduos quanto inspeciona a saúde e a higiene do corpo-organismo social, assegurando-se enquanto saber oficial sobre os corpos (LE BRETON, 2003).

Nos fins do século XIX e nas primeiras décadas do século XX, as grandes metrópoles são assoladas pelas iniciativas da medicina higiênica e seus grandes planos de intervenção sanitária, intentando "esterilizar" todo o corpo social de possíveis elementos nocivos à saúde pública. Nocividade, que convenhamos, estava quase sempre associada às classes marginalizadas e às áreas periféricas das cidades; daí a grande quantidade de despejos e demolições realizadas em cortiços, conjuntos habitacionais, pensões, prostíbulos ou outras construções em bairros pobres, aliados ao medo generalizado da "mestiçagem", de uma possível degenerescência no biótipo da raça mais forte (impreterivelmente, o homem branco, consumidor - europeu ou descendente) caso ela viesse a misturar-se com outras menos "civilizadas" (imigrantes produtores, escravos etc.) (COSTA, 1989).

Políticas nacionalistas e desenvolvimentistas fazem da Educação Física um dever nacional patriótico, um imperativo viril e civil da raça que tanto mais aperfeiçoa seu caráter e sua força quanto mais delega seus corpos às ginásticas estatais. Do pioneirismo de F. Jahn, na Prússia do século XIX, à Alemanha nazista de Hitler; do Estado fascista de Mussolini ao Estado Novo getulista, a disciplina corporal militar é recodificada para o plano civil, através da medicina, e difundida em toda a sociedade disciplinar. Nas Olimpíadas de Berlim em 1936, auge do nazismo (e do racismo de Estado), Hitler recusara-se a entregar as medalhas de ouro ao atleta negro americano Owen Wilson, vencedor de quatro modalidades olímpicas. Para o führer nazista o que subia ao pódio era toda a negação do ideal da superioridade ariana, a subjugação política do corpo germânico a uma raça "de direito" inferior.

\section{O CORPO NA "PÓS-MODERNIDADE" - CORPO MERCADORIA E CORPO RASCUNHO}

Hoje, onde estamos? Muitos dirão que em algum lugar que não mais a Modernidade. Dr. Tulp e sua comitiva moderna decerto estranhariam a operação de implantação de próteses de silicone nas clínicas estéticas contemporâneas, mas provavelmente não ficariam menos confusos ao sair desta para a rua, pisando o asfalto da "pós-modernidade".

A expressão "pós-modernidade" sugere, de uma maneira geral, a mudança de uma época para outra (como é patente pelo emprego do prefixo "pós"), implicando numa interrupção da era moderna e no surgimento de "uma nova totalidade social, com seus princípios organizadores próprios e distintos" (FEATHESTONE, 1995, p.20). Esta ruptura histórica se encontra comumente relacionada com as transformações sociais, culturais, econômicas e políticas do início dos anos 1960, tais como os movimentos estudantis radicais (o Maio 68 na França, p.ex.); a irrupção 
de movimentos reivindicatórios de minorias, os movimentos "pós-modernistas"4 no campo da arte, da arquitetura, da literatura e da academia; a ascensão vertiginosa das tecnologias de comunicação respaldadas pelos novos recursos da informática; a queda do "socialismo real" e o estabelecimento de um mundo exclusivamente dominado pela economia de mercado capitalista, juntamente com a expansão, sem precedentes, da chamada "globalização".

Sugere também um conjunto heterogêneo de mudanças, rupturas e hibridações que vem questionar noções filosóficas básicas da modernidade, como os conceitos iluministas de "Verdade", "Razão Universal", "Individualidade", "Progresso" e "Emancipação Humana pela Ciência" (EAGLETON, 1998). Comumente, associa-se a emergência da "pós-modernidade" às turbulentas reviravoltas do "breve século XX", como diria Hobsbawm (1995), o que não exclui as dificuldades e imprecisões inerentes a qualquer tentativa de "localizar" o ponto de gênese temporal desse complexo acontecimento histórico-cultural, como demonstram as diversas denominações empreendidas por diferentes teóricos na tentativa, ressalte-se, não consensual, de determinar diferenças entre a atualidade e a chamada modernidade clássica: "sociedade pós-industrial" (BELL, 1973), "pósmodernidade" (LYOTARD, 1979), "modernidade tardia" (GIDDENS, 1997), "sociedade programada" (TOURAINE, 1994), "alta modernidade" (CASTELLS, 1999), "modernidade líquida" (BAUMAN, 2001), "hipermodernidade" (LIPOVETSKY, 2004), dentre outros.

De todo modo, essa gama de mudanças e transformações seria imanente às novas configurações assumidas pela faceta contemporânea do capitalismo, como o desenvolvimento acelerado de novas tecnologias de produção e a fabricação e manutenção de um imenso mercado consumidor para o escoamento massivo dos produtos, que para efetivar-se necessita de todo um sistema de "educação" para o consumo, função prontamente realizada pela indústria cultural ${ }^{5} \mathrm{e}$ seu grande tentáculo: a publicidade (SEVERIANO, 2001). Esta impregnação da esfera cultural e subjetiva, acentuada com a globalização, faz com que a subjetividade (cada vez mais aderida ao corpo), seus afetos e seu imaginário sejam os alvos por excelência da nova lógica de consumo capitalista (PELBART, 2000; KLEIN, 2004).

Ao longo do século XX, percebe-se um inquieto movimento de "resgate" da corporeidade, de revalorização e reformulação de sua dimensão, tendendo a relações (à primeira vista) mais livres e emancipadas entre os corpos, a sociedade e a cultura. Principalmente a partir da segunda metade do século, o corpo parece desertar dos batalhões disciplinares, das grandes e rigorosas estratégias estatais, numa recusa veemente a ceder sua vida a terceiros (o Estado, as Forças Armadas, a Indústria etc.). Já não se exige tanto ao corpo do indivíduo que "sirva", na condição de produtor, como nos paradigmas maquínicos dos séculos XVII ao XIX, mas que o indivíduo "ponha-se a serviço" do próprio corpo, que consuma os mais diversificados objetos e serviços produzidos pela incipiente indústria da saúde e da beleza (BAUDRILLARD, 1970). A marionete dócil, sóbria e disciplinada da era moderna parece desprender-se de suas amarras morais e de quaisquer nós que limitem o livre dançar de seus movimentos. 
Entretanto, como nos afirmou Baudrillard (1970, p. 93-95):

O consumo surge como conduta ativa e coletiva, como coação e moral, como instituição. Compõe todo um sistema de valores, com tudo o que este termo implica enquanto função de integração do grupo e de controle social. [...] A abundância e o consumo não surgem, portanto, como a realização da Utopia. Constituem nova situação objetiva, regulada pelos mesmos processos fundamentais, mas sobredeterminada também por nova moral. [...] O indivíduo serve ao sistema industrial, não pela oferta das suas economias e pelo fornecimento de capitais, mas pelo consumo dos seus produtos. Por outro lado, não existe qualquer outra atividade religiosa, política ou moral, para a qual seja preparado de maneira tão completa, tão científica e tão dispendiosa.

Acompanha-se, desta forma, uma incessante operação de captura do corpo - suas dores e delícias - pela indústria cultural, transformando o corpo-produtor em corpo-consumidor, e assim tornando-o uma rentável especiaria a se vender no mercado. Sim, o corpo hoje é o mais "belo objeto de consumo" (BAUDRILLARD, 1970), aquele pelos quais imensos sacrifícios são realizados e vultosos investimentos são canalizados.

Ante essa atenuação das normas de decoro dos corpos, sua incensada liberação do maquinário ortopédico de outrora e sua captura pelo capital enquanto objeto de consumo desejável, que relações de poder estariam implicadas? Vejamos estes fenômenos à luz da relação produção x consumo.

Em linhas gerais, o capitalismo dos séculos XVII a XIX funcionou sob o primado da produção, condição indispensável à própria expansão de seu aparato industrial e consolidação de sua economia (SEVERIANO, 2001). A vida, organizada em torno da produção, tende a ser encurralada entre limites e normas mais explícitos e estatuídos (BAUMAN, 2001), no sentido de conformar os comportamentos a parâmetros mínimos de funcionalidade (condições de empregabilidade, regras para o consumo, normas de produtividade etc.). A difusão dos dispositivos disciplinares à época vem cumprir essa exigência por normatizar os usos dos corpos, talhando-os às exigências do capital, por meio da incessante vigilância panóptica perpetrada por grandes e estratégicas instituições sociais: as escolas, as fábricas, o exército etc.

A crise de superprodução nos países mais industrializados, cujo evento emblemático foi o crack da bolsa de valores de Nova York em 1929, acarretou extensas reformulações na estrutura do modo de produção capitalista. A manutenção de um mercado de consumo massivo para a superabundância de mercadorias exige novos padrões de comportamento, um tanto distante das regulações normativas massivas e coercitivas de uma vida organizada em torno da produção.

O que aí observamos é o surgimento de um novo ethos, não mais orientado pela moral puritana e racional do capitalismo nascente, mas baseado num modelo hedonista e lúdico, cujos valores fundamentam-se na "auto-realização" e na "feli- 
cidade", buscadas no próprio ato de consumir. A idéia de que a individualidade pode (e deve) forjar-se nas referências sociais da lógica do consumo aparece como uma alternativa socialmente valorizada, observando-se, desde aí, uma forte voracidade pela possessão em si de mercadorias como fator de distinção social.

Não mais a parcimônia no consumo como à época dos primeiros produtores norteados pela ética protestante (WEBER, 1997), pautados primordialmente pelo valor de uso e pela funcionalidade dos produtos, mas o desejo irrefreável de consumir de forma "personalizada", considerando agora os objetos sedutoramente publicizados em seu "valor de signo" (BAUDRILLARD, 1976). ${ }^{6}$

Tal fenômeno evidencia-se na preocupação acentuada, proveniente de todos os campos, com a realização individual privada em estreita ligação com as opções do consumidor, na qual, não apenas a beleza, mas a individualidade, a segurança, o sentimento de pertença, o reconhecimento social, a felicidade, enfim, passam a ser cada vez mais exibidos pela indústria cultural como um bem a ser adquirido através do consumo. Os fluxos de desejo constantemente instigados são prontamente capturados num sistema de "imagens de marcas" intensamente fetichizadas. Aqui não se vende meramente um produto em seu valor de uso ou funcionalidade, vendem-se principalmente atributos subjetivos desejáveis, supostamente emanados originalmente dos produtos. Neste sentido, a identidade do sujeito passa a subordinar-se, cada vez mais, à apropriação dos signos de consumo, os quais se investem de um papel crucial na produção de subjetividades, modelando e legitimando comportamentos, estéticas, valores, atitudes e estilos de vida, numa lógica capitalista que extravasa seus poderes de manipulação para além dos muros da fábrica. A expansão do tempo de lazer, por exemplo, oriunda de históricas conquistas trabalhistas, como as férias remuneradas (décimo terceiro salário) e a redução da jornada de trabalho, ao gerarem novos espaços cotidianos destinados ao ócio, nos quais os corpos poderiam travar relações menos restritas aos circuitos normatizadores da produção, tornaram-se, não obstante, elementos prontamente detectados e explorados pela indústria cultural em seu vertiginoso processo de expansão (ADORNO; HORKHEIMER, 1991). Para Adorno et al. (1983, p. 13):

[...] através da indústria cultural o próprio ócio do homem teria se tornado uma mera extensão do trabalho, tendo por finalidade última sua mecanização, uma sucessão automática de operações reguladas. [...] só se pode escapar ao processo de trabalho na fábrica e na oficina, adequando-se a ele no ócio.

Assim vemos historicamente os prazeres do corpo, seu bem-estar, seu deleite narcísico passarem a alimentar diretamente a faminta sociedade de consumo. A evolução da moda dá provas disso. A bermuda de escoteiro na década de 1920; o jeans, nos anos 1940; os biquínis nos anos 1950; a minissaia na década de 1960; o monoquíni e a difusão dos trajes esportivos (sportswear), entre os anos 1970 e 1980, constituem-se em um desfile de revoluções de hábitos e costumes no qual o corpo ganha leveza e visibilidade, ao tempo em que a indústria da moda engorda e fatura pesadamente (PROST; VINCENT, 1992). A aparência passa a depender cada vez mais do corpo e da sua silhueta e não de vestes que simbolizem status ou 
hierarquias (fardas, trajes de gala, indumentárias aristocráticas etc.), mas que ressaltem formas e curvas corporais.

Os ideais corporais circulam agora preferencialmente entre as extensas redes da mídia e da publicidade. O velho olho panóptico, cuja autoridade e poder funcionavam mais no confinamento típico das instituições disciplinares, desdobra-se, ramifica-se e ganha mil filhotes mais astutos e atentos, difusos no espaço cotidiano. A disciplina, descontínua (pois contingente aos meios de confinamento) e inflexível (pois institui "moldes" fixos e emprega a repressão como principal instrumento de modelagem) cede lugar ao controle, contínuo (difuso e generalizado) e mais flexível (visto que age por modulações constantes e tende a funcionar com mais sutileza e eficácia, por estimulação) como diagrama privilegiado das relações de poder na contemporaneidade (DELEUZE, 1992; FONSECA; ENGELMAN, 2004). O corpo submete-se a um mapa de cuidados contínuos e infinitos, uma "bioascese" (ORTEGA, 2002), na qual é imperativo purificá-lo de qualquer ameaça à sua juventude, força e beleza. O novo higienismo, iniciado em larga escala pela "geração saúde" da década de 1980, alimenta-se da próspera indústria de produtos lights e diets e de toda uma série de alimentos-remédio polivalentes (SANT'ANNA, 2001) - comidas superenriquecidas, complexos vitamínicos, suplementos metabólicos e alimentos-cosméticos, tais como: iogurtes anti-rugas, bebidas tônicas rejuvenescedoras etc. - rechaçando a carne vermelha, a fritura, o açúcar e tudo o que extrapole um limiar estabelecido de calorias. Academias, clínicas estéticas e spas são empreendimentos que primam por uma oferta "terapêtica" massiva ao "corpo-rei" para que este se cerque de prazeres, conforto e jovialidade, afastando-o do fantasma onipresente do "estresse" - a peste contemporânea que o envelhece e reduz seu prazo de validade. "Tornamo-nos, dessa forma, politeístas, tolerantes, sexualmente liberados e complacentes com as pequenas transgressões morais, desde que nada disso desequilibre as taxas de colesterol" (COSTA, 2004, p. 191).

Neste registro, o corpo passa a ser fonte inesgotável de promessas e prazeres. A fronteira rígida entre saúde e patologia, expressa numa concepção de beleza enquanto estado corporal saudável, capaz de ser medido e inferido por diagnósticos médicos, parece desaparecer com o atual apelo a estados subjetivos e particulares de satisfação, dando lugar ao que Bauman (2001, p. 91-92) denominou de "aptidão" (tradução do termo inglês fitness, que também é empregado no Brasil como sinônimo de malhação ou de exercícios corporais em geral):

[...] "estar apto" significa ter um corpo flexível, absorvente e ajustável, pronto para viver sensações ainda não testadas e impossíveis de descrever de antemão. [...] "Aptidão" significa estar pronto a enfrentar o não-usual, o não-rotineiro, o extraordinário - e acima de tudo o novo e o surpreendente. [...] A busca de aptidão não tem portanto, um fim natural. Os objetivos podem ser estabelecidos apenas para a presente etapa do esforço sem fim [...] A busca da aptidão é um estado de auto-exame minucioso, auto-recriminação e autodepreciação permanentes, e assim também de ansiedade contínua. 
Trata-se de uma psicologização irrefreada dos estados corporais e da transformação da saúde em uma experiência subjetiva vinculada a ideais externos modelos e celebridades midiáticas, em que o ajuste de uma parte específica do corpo - lipoaspiração de uma gordurinha localizada, lifting para apagar marcas da idade - afeta toda a estrutura psíquica do indivíduo, devolve-lhe a "auto-estima", aumenta sua "confiança-em-si-mesmo" ou resgata seu "prazer de viver e amar". A ênfase agora recai sobre a vontade, a capacidade de estar no controle de seu corpo e mente para atingir a prometida "qualidade de vida" (COSTA, 2004). "Você pode, basta querer" - um escritor de auto-ajuda em cada academia... De todo modo, é preciso querer, é preciso estar "apto". A nova figura do anormal é o "estulto", o mau exemplo encarnado da incompetência e da fraqueza da vontade em consumir "adequadamente" (segundo normas e padrões cada vez mais exigentes) objetos e serviços que the aproximem do "corpo ideal" (COSTA, 2004), uma vez que "ofertas" não lhe faltam. Viciados, anoréxicos, bulímicos e obesos são segregados como outrora ocorriam nos leprosários ou incluídos em circuitos perversos, sempre disponíveis às investidas do humor, da ironia, do grotesco, do escândalo, da polêmica, da piedade etc.

O que parece escapar aos atestados individuais de estultícia é toda a nova realidade que emerge a partir da "cultura somática" (COSTA, 2004) de nossos dias, uma cultura que se define pelo imperativo moral da sensorialidade, da facticidade corporal, em contraposição à "educação sentimental" burguesa, própria do início da Modernidade. Para este autor:

A personalidade somática tem na imagem social do corpo o suporte, por excelência, do caráter ou da identidade. [...] Se deixa adestrar com a mesma docilidade com que o indivíduo sentimental aprendeu a renunciar à sensualidade em proveito das emoções romanticamente sublimadas. (COSTA, 2004, p.194-195)

Esse corpo tornou-se hoje o santuário privilegiado da subjetividade humana, a via régia para a obtenção de sucesso, felicidade, realização profissional e afetiva, sob a condição de obediência à nova disciplina imposta pelos conglomerados industriais da saúde e do fitness. Em face disso, torna-se imperativo escancarar cada um de seus poros para que absorvam as efêmeras novidades da indústria de alimentos, cosméticos e da moda (é preciso pressa, pois o verão está chegando...), assim como as receitas e manipulações corporais, cada vez mais sofisticadas da medicina estética e do fitness, com o risco sempre presente de esse corpo tornar-se material obsoleto, sempre retardatário às mais novas festas de felicidade e euforia, ofertadas pelo mercado. Daí a mais recente figura do corpo ser denominada de “corpo-rascunho" (LE BRETON, 2003), amontoado instável e assimétrico de pele, músculos, ossos e cabelos eternamente em busca do desenho perfeito; não obstante, sempre em estado de rascunho, pois o encalço ao corpo perfeito, ideal, precisa ao menos esperar a cicatrização dos pontos da cirurgia e o relaxamento das cãibras musculares para seguir sua maratona infinita.

Se outrora a alma ou o espírito foram as sedes impalpáveis e invisíveis da subjetividade e identidade humanas, estas hoje expõem fotogenicamente suas si- 
lhuetas às milhares de lentes invisíveis que expõem o corpo a uma sabatina incessante de controle, vigilância e cobrança. A antropometria vitoriana certamente se comprazeria ao ver que seu esforço em colar a subjetividade à anatomia humana não se gastou em vão, mas quedaria boquiaberta diante da eficácia com que esta tarefa foi levada a cabo no capitalismo tardio, segundo meios que deixam a medicina criminalista e a eugenia nazista parecendo ensaios desajeitados.

\section{REFLEXõES FINAIS}

"Podemos expor o corpo com menos pudores do que no passado, mas há novos pudores em gestação"

(SANT'ANNA, 2001, p.69)

Dr. Tulp, o anfiteatro renascentista e a turba de burgueses curiosos. A clínica estética, o cirurgião e seu assistente em trajes assépticos. Em ambas as cenas - Moderna e "Pós-Moderna" - um corpo ocupa o centro de todas as atenções. No quadro de Rembrandt, é um cadáver que é depositado no leito, pálido, rijo, saído de algum patíbulo direto para a aula de anatomia do renomado doutor. Certamente um corpo indigente que logo voltará à penumbra e ao esquecimento em alguma vala comum, assim que sua função expirar. O corpo no leito da clínica estética atual está vivo ainda que sedado e anestesiado - e sairá da sala de cirurgia para a luz, para os flashes, para o mundo do "espetáculo", um mundo em que os longínquos descendentes da comitiva de Dr. Tulp desfilam e voltam seus olhares sempre curiosos (heranças antepassadas?) às silhuetas que porventura cruzem seu campo de visão.

O corpo, superfície privilegiada de inscrição da história, não consegue disfarçar impunemente as marcas deixadas pelos diferentes usos e desusos que recebeu no longo percurso que o leva à contemporaneidade. Corpo-máquina/corpoprodutor, corpo-mercadoria/corpo-consumidor, todos eles ainda pulsam como inconvenientes hematomas no corpo sarado e hedônico de hoje; coexistem em todos, ainda, as marcas do controle social, seja de forma heterônoma, seja por suposta vontade própria.

Não cabe aqui tentar traçar esquemas maniqueístas que estabeleçam o "bom corpo" em oposição a todos os outros que o antecederam ou o sucederão, essencialmente "maus" e inadequados. Algumas conquistas do corpo contemporâneo são significativas, mas no seio destas vitórias, novas batalhas já se desenham. A propalada "liberalização" dos corpos, na contemporaneidade, não os exime da servidão restrita a novos senhores: os regimes de corporeidade ditados pelo imenso mercado de desejos e sensações; uma "bioascese", plena de prescrições e modelos ideais a serem atingidos a qualquer custo, cuja violência característica consiste justamente em responsabilizar unicamente o indivíduo pela sua inaptidão e fracasso no alcance destes ideais.

A esse respeito vale lembrar o que Alain Ehrenberg, em seu livro La fatigue d'Être Soi: Dépression et Société (1998) denominou de o "homem insuficiente", cuja angústia neurótica é proveniente não da interdição do seu desejo por uma or- 
dem objetiva, mas seu sofrimento é oriundo, justamente, da sensação de insuficiência e incapacidade para fazer frente ao excesso de possibilidades, às exigências cada vez mais intensas e urgentes demandadas pela atual sociedade de consumo.

As singularidades são, desta forma, assaltadas pelas constantes tentativas de captura do mercado. A análise dos diversos registros do corpo ao longo da Modernidade/"Pós-modernidade" parece desfiar o inconveniente fio de Ariadne que ata acontecimentos históricos tão dispersos no tempo: o minotauro capitalista e suas vicissitudes. Estaríamos fadados a cumprir o diagnóstico proferido por Adorno e Horkheimer (1991), acerca do engodo do novo no capitalismo em tempos de indústria cultural? Qual seja:

A máquina gira sem sair do lugar. Ao mesmo tempo que já determina o consumo, ela descarta o que ainda não foi experimentado porque é um risco. [...] Nada deve ficar como era, tudo deve estar em constante movimento. Pois só a vitória universal do ritmo da produção e reprodução mecânica é a garantia de que nada mudará, de que nada surgirá que não se adapte (ADORNO; HORKHEIMER, 1991, p.126).

Não é bem o que cremos, nem o que desejamos. Apesar das evidências atuais de uma indústria cultural ainda homogeneizadora acreditamos na possibilidade de um "corpo-devir" ser sempre possível e tangível, como bem apontam as furtivas estratégias de boicote aos estratagemas capitalistas via movimentos sociais multifacetados, principalmente no plano micropolítico, bem documentadas por Klein (2004). Nos interstícios dos "poderes superiores" do capitalismo globalizado, o Aqueronte não para de se agitar, e para não esquecer Deleuze (1992, p. 220) "não cabe temer ou esperar, mas buscar novas armas"; ampliar os corpos possíveis (e desejáveis), fazê-los ressoar e proliferar dentro e fora das redes de poder que os espreitam, minando-as e reinventando-as no processo.

Curiosamente, a pergunta que surge como fundamental em tempos de supervalorização e superexigência calculada dos corpos vem de um filósofo contemporâneo de Dr. Tulp, Spinoza (1632-1677, portanto, nascido no ano da pintura do quadro de Rembrandt...): afinal, "o que pode o corpo?” (SPINOZA, 1965). E mais além, o que queremos poder fazer desse corpo?

\section{Notas}

\footnotetext{
1 Utilizamos os termos Modernidade e "Pós-Modernidade" com fins eminentemente didáticos, por tratar-se de conceitos empregados com bastante freqüência na literatura acadêmica. Contudo, é necessário ressalvar que, ao longo do presente texto, não tomamos tais conceitos como momentos históricos radicalmente distintos e incomunicáveis, reconhecendo as continuidades (principalmente no tocante à permanência em ambos do mesmo modo estrutural de produção, o capitalismo e seus dispositivos infra-estruturais) e descontinuidades que perfazem seus contextos (daí o emprego de aspas no termo "Pós-Modernidade", denotando uma não apropriação do mesmo), entendendo, ainda, a temporalidade histórica não como uma linha uniforme e progressiva, uma seta que partiria naturalmente de uma antiguidade primitiva em direção a uma modernidade civilizada e esclarecida, mas como um arranjo de ligação temporário (produzido socialmente) entre elementos de uma determinada cultura. Cf. Latour (1994) e Stenger (2002).
} 
2 Em 1868, Charles Baudelaire é o primeiro a utilizar o termo modernidade. Em seu ensaio El pintor de la vida moderna ele descreve a modernidade como a atitude do dandy, oflâneur, o ocioso dotado de uma sensibilidade própria, que contempla a vida ao seu redor. Dominado por uma insaciável paixão por ver e sentir, amante do mundo, seu elemento é a multidão. Para Baudelaire a modernidade é o reflexo do eterno e do imutável na arte, ao mesmo tempo que significa o efêmero, o fugidio e o contingente.

3 Descartes (1976) em seu Traité du Monde et de L'Homme aponta que a única diferença entre o corpo do animal e o corpo humano adviria, segundo esta concepção, da ligação entre este último e sua alma, através da glândula pineal, por onde a alma teria a sensação de todos os movimentos produzidos pelo corpo.

4 O termo "pós-modernismo" foi utilizado pela primeira vez por Federico de Onis, na década de 1930, para indicar uma reação de menor importância ao modernismo. Popularizou-se na década de 1960 em Nova York, quando passou a ser usada por jovens artistas, escritores e críticos para designar um movimento para além do alto-modernismo, considerado já "esgotado" e rejeitado por sua institucionalização no museu e na academia. Nas décadas de 1970 e 1980, o termo foi amplamente utilizado na arquitetura, nas artes visuais e cênicas, assim como na literatura e na música, findando por ser apropriado pela publicidade e se disseminar no próprio modo de produção capitalista (HARVEY, 1989).

5 Em 1947, por ocasião da publicação da obra A Dialética do Esclarecimanto, Adorno e Horkheimer cunharam o termo "Indústria Cultural", a fim de substituir a expressão, então em uso, de "cultura de massa". Negando ambos os termos da expressão, ou seja, nem "cultura" nem "massa", eles denunciaram a impossibilidade de haver qualquer vestígio de igualdade entre "cultura de massa" e democratização da cultura ao sublinhar o caráter compulsório da indústria cultural por eles concebida como "a integração deliberada, a partir do alto, de seus consumidores" (ADORNO; HORKHEIMER, 1991, p.131), na qual é suprimida tanto a complexidade da "cultura erudita" quanto a rudeza espontânea da cultura popular que permitia resistir ao controle da "sociedade administrada".

6 Segundo Baudrillard (1976), a lógica que preside a atual relação do homem com os objetos de consumo se baseia, preponderantemente, no "valor-signo" dos objetos e não mais em seu valor de uso ou de funcionalidade, o qual se fundava num sistema de necessidades racionais e objetivas do consumidor. De acordo com o autor, esta lógica do "valor-signo" é orientada por um sistema distintivo de imagens de marca, ditada pela moda, cujo sentido não está mais referido a nenhuma relação humana, mas sim à relação diferencial entre signos, que se hierarquizam de acordo com os atributos subjetivos e de prestígio social agregados ao produto.

\section{REFERÊNCIAS}

ADORNO, T.; HORKHEIMER, M. Dialética do esclarecimento. 3. ed. Rio de Janeiro: J. Zahar, 1991.

ADORNO, T. et al. Textos escolhidos. São Paulo: Abril Cultural, 1983. (Os pensadores).

BAUDELAIRE, C. El pintor de la vida moderna. Murcia: Colegio Oficial de Aparejadores y Arquitectos Técnicos, 1995.

BAUDRILlARD, J. A sociedade de consumo. São Paulo: Martins Fontes, 1970. La génesis ideológica de las necesidades. Barcelona: Anagrama, 1976.

BAUMAN, Z. Modernidade líquida. Rio de Janeiro: J. Zahar, 2001.

BELL, D. O advento da sociedade post-industrial. Madrid: Alianza, 1973.

CASTELLS, M. A sociedade em rede. São Paulo: Paz e Terra, 1999. 
COSTA, J. F. História da psiquiatria no Brasil. 4. ed. Rio de Janeiro: Xenon, 1989.

O vestígio e a aura. Rio de Janeiro: Garamond, 2004.

DESCARTES. R. Traité de monde et de l'homme. Paris: Gallimard, 1976.

DELEUZE, G. Conversações. Rio de Janeiro: Ed. 34, 1992.

EAGLETON, T. As ilusões do pós-modernismo. Rio de Janeiro: J. Zahar, 1998.

EHRENBERG, A. La fatigue d'être soi: Depressión et Société. Paris: Odile Jacob, 1998.

FEATHERSTONE, M. Cultura do consumo e pós-modernismo. São Paulo: Studio Nobel, 1995.

FIGUEIREDO, L. C. M. A invenção do psicológico: quatro séculos de subjetivação (1500-1900). 6. ed. São Paulo: Escuta, 2002. . Matrizes do pensamento psicológico. 8. ed. Petrópolis: Vozes, 2000.

FONSECA, T. M. G.; ENGELMAN, S. (Org.). Corpo, arte e clínica. Porto Alegre: UFRGS, 2004.

FOUCAULT, M. História da sexualidade I: a vontade de saber. 16. ed. Rio de Janeiro: Graal, 2005. . Vigiar e punir. 20. ed. Petrópolis: Vozes, 1999.

GIDDENS, A. Modernidade e identidade. Rio de Janeiro: J. Zahar, 1997.

GONÇALVES, A. G. B. A plasticidade dos usos sociais do corpo de classes populares em São Luis. 2002. Tese (Doutorado)-Programa de Pós-Graduação em Sociologia da Faculdade de Ciências e Letras de Araraquara, Universidade do Estado de São Paulo, Araraquara, 2002.

HARDT, M.; NEGRI, A. Império. 6. ed. Rio de Janeiro: Record, 2004.

HARVEY, D. Condição pós-moderna. São Paulo: Loyola, 1989.

HOBSBAWM, E. Era dos extremos: o breve século XX - 1914-1991. São Paulo: Companhia das Letras, 1995.

KLEIN, N. Sem logo: a tirania das marcas em um planeta vendido. 4. ed. Rio de Janeiro: Record, 2004.

LATOUR, B. Jamais fomos modernos: ensaio de antropologia simétrica. Rio de Janeiro: Ed. 34, 1994.

LE BRETON, D. Adeus ao corpo: antropologia e sociedade. São Paulo: Papirus, 2003.

LIPOVETSKY, G. Os tempos hipermodernos. São Paulo: Barcarolla, 2004.

LYOTARD, J. F. A condição pós-moderna. Rio de Janeiro: J. Olympio, 1979. 
MARX, K. Fetichismo e reificação. In: IANNI, O. (Org.) Sociologia. São Paulo: Ática, 1984. p.159-172.

ORTEGA, F. Da ascese à bio-ascese: ou do corpo submetido à submissão ao corpo. In: RAGO, M.; ORLANDI, L. B. L.; VEIGA-NETO, A. (Org.). Imagens de Foucault e Deleuze: ressonâncias nietzschianas. Rio de Janeiro: DP\&A, 2002.

PELBART, P. P. A vertigem por um fio: políticas de subjetividade contemporânea. São Paulo: Iluminuras, 2000.

PERROT, M. (Org.). História da vida privada 4: da Revolução Francesa à Primeira Guerra. São Paulo: Companhia das Letras, 1991.

PROST, A.; VINCENT, G. (Org.). História da vida privada 5: da Primeira Guerra aos nossos dias. São Paulo: Companhia das Letras, 1992.

REMBRANDT van R. The Anatomy Lesson of Dr. Nicolaes Tulp. 1632. Oil on canvas; in the Collection of Mauritshuis, The Hague. $169.5 \times 216.5 \mathrm{~cm}$.

SANT'ANNA, D. B. (Org.). Corpos de passagem. São Paulo: Estação Liberdade, 2001.

Políticas do corpo. São Paulo: Estação Liberdade, 1995.

SEVERIANO, M. de F. V. Narcisismo e publicidade: uma análise psicossocial dos ideais do consumo na contemporaneidade. São Paulo: Annablume, 2001.

SPINOZA, B. Étique. Paris: Flammarion, 1965.

STENGERS, I. A invenção das ciências modernas. Rio de Janeiro: Ed. 34, 2002.

TOURAINE, A. Crítica da modernidade. Petrópolis: Vozes, 1994.

WEBER, M. A ética protestante e o espirito do capitalismo. São Paulo: Pioneira, 1997.

Recebido em: julho/2006

Aceito em: novembro/2006 
